\title{
Verification and validation of ShipMo3D ship motion predictions in the time and frequency domains
}

\author{
Kevin A. McTaggart \\ Defence Research and Development Canada - Atlantic, Dartmouth, Nova Scotia, Canada
}

\begin{abstract}
This paper compares frequency domain and time domain predictions from the ShipMo3D ship motion library with observed motions from model tests and sea trials. ShipMo3D evaluates hull radiation and diffraction forces using the frequency domain Green function for zero forward speed, which is a suitable approach for ships travelling at moderate speed (e.g., Froude numbers up to 0.4). Numerical predictions give generally good agreement with experiments. Frequency domain and linear time domain predictions are almost identical. Evaluation of nonlinear buoyancy and incident wave forces using the instantaneous wetted hull surface gives no improvement in numerical predictions. Consistent prediction of roll motions remains a challenge for seakeeping codes due to the associated viscous effects.
\end{abstract}

KEY WORDS: Frequency domain; Seakeeping; Ship motions; Time domain; Validation.

\section{INTRODUCTION}

The Canadian Navy routinely operates in heavy seaway conditions, and ship motion predictions are often required for applications such as design, maintenance support, operational guidance, and training. In recent years, ship motion simulations have been coupled with simulations of other systems to model complex scenarios, such as replenishment at sea (McTaggart and Langlois, 2009).

Strip theory (Salvesen, Tuck and Faltinsen, 1970) has been used for many years by the Canadian Navy, and provides surprisingly good motion predictions for slender naval vessels. Roll motion has a significant impact on naval operations; thus, significant attention has been given to modelling of viscous and appendage lift forces influencing roll motion (Schmitke, 1978; and Himeno, 1981). The strip theory code SHIPMO7 (McTaggart, Datta, Stirling, Gibson, and Glen, 1997) continues to be used for routine frequency domain computations.

The Canadian Navy has been involved in international efforts developing the time domain code FREDYN for simulation of ship capsize with the aim of developing new stability criteria (de Kat, Brouwer, McTaggart, and Thomas, 1994). FREDYN has been coupled with a probabilistic method to evaluate capsize probability (McTaggart and de Kat, 2000). Evaluation of hull hydrodynamic forces in FREDYN was originally based on strip theory, with a panel

Corresponding author: Kevin A. McTaggart

e-mail: kevin.mctaggart@drdc-rddc.gc.ca method now being available. When considering the application of time domain codes to evaluation of ship capsize in severe conditions, it should be noted that only limited validation of numerical predictions has been done.

The ShipMo3D ship motion library has been developed during the past several years and provides predictions in both the frequency and time domains. Hull hydrodynamic coefficients are evaluated using a panel method, which is intended to give reliable motion predictions for both slender and non-slender hull geometries. The ShipMo3D library is described in greater detail in the next section.

Numerical predictions are routinely validated using results from model tests and sea trials. The National Research Council of Canada Institute for Ocean Technology in St. John's, Newfoundland often conducts model test programs for the Canadian Navy, such as experiments on a hydroelastic frigate model (McTaggart, Datta, Stirling, Gibson, and Glen, 1997) to examine motions and sea loads in moderate and severe conditions. Defence Research and Development Canada often performs dedicated sea trials to measure motions and hull strains, such as those described by Stredulinsky, Pegg, and Gilroy (2000).

\section{SHIPMO3D LIBRARY FOR SHIP MOTIONS IN THE FREQUENCY AND TIME DOMAINS}

The ShipMo3D library has been developed for predicting ship motions in the frequency and time domains. ShipMo3D fulfills the following main objectives: 
- suite of robust applications for ship motion analysis aimed toward both expert and non-expert users,

- object-oriented library suitable for various simulation applications, including integration with High Level Architecture simulations (Kuhl, Weatherly, and Dahmann, 1999; McTaggart and Langlois, 2009),

- object-oriented library that can be used for implementation and testing of ship motion analysis methods.

The selection of approaches for evaluation of ship motions is very dependent on requirements. ShipMo3D is aimed at providing accurate motion predictions for the following:

- both slender and non-slender hull geometries,

- moderate ship speeds (e.g., Froude numbers $\leq 0.4$ ),

- moderately severe wave conditions (e.g., naval frigates in up to $7 \mathrm{~m}$ significant wave height),

- computation speed of real-time or faster for time domain simulations.

\section{Theoretical Background}

Hull hydrodynamic forces are computed in the frequency domain using the zero-speed Green function, similar to the approach used by Papanikolaou and Schellin (1992). This approach gives robust and accurate results for vessels travelling at moderate speeds (Schellin, Chen, Beiersdorf and Maron, 2002). To enable evaluation of ship motions in the time domain, hull force retardation functions are determined from frequency domain radiation coefficients (Wehausen, 1971).

Viscous and lift forces acting on appendages are evaluated based on the work of Schmitke (1978) and Himeno (1981). For frequency domain computations, hull and appendage viscous forces are dependent on roll amplitude, which is evaluated iteratively for each combination of ship speed, ship heading, and seaway. For time domain computations, bilge keel drag coefficients can be dependent on nominal roll amplitude or roll velocity amplitude, which can be determined based on the recent history of vessel motions.

Hull maneuvering forces are considered when evaluating motions in both the frequency and time domains, and are evaluated using the approach of Inoue, Hirano, and Kijima (1981). Care has been taken to avoid duplication of terms when merging hull maneuvering and seakeeping force terms.

When computing ship motions in the time domain, buoyancy and incident wave forces acting on the hull can be computed using either linear terms or using pressures evaluated on the instantaneous wetted surface. For full-scale ships, time domain predictions typically run faster than realtime, even when using nonlinear buoyancy and incident wave forces.

\section{Software Implementation}

Selection of a programming language has a large impact on subsequent development for a large project such as a ship motion library. The following were considered essential when selecting a programming language for ShipMo3D:

- object-oriented,

- ease of programming, including automated garbage collection,

- support for numerical programming, including complex numbers,

- availability of numerical libraries, including linear algebra,

- high computation speed.

Version 1 of ShipMo3D was developed using Python (McTaggart, 2006), which is widely used for scientific programming. Python is a dynamically typed language, meaning that the type for a variable doesn't need to be declared, but is instead determined at run-time. For example, a variable $\mathrm{x}$ can be introduced as follows:

$\mathrm{x}=1.0$

In contrast, a statically-typed language (e.g., C, C++, C\#, Fortran, or Java), requires that a type be declared for each variable, such as shown in the following example:

double $x$;

$\mathrm{x}=1.0$;

A dynamically typed language such as Python often has advantages with respect to conciseness of code; however, dynamically typed languages typically give slower execution speeds than statically typed languages.

Version 2 of ShipMo3D has been developed using C\#. Transition of code from Python to C\# was relatively easy, and was assisted by an in-house code conversion program. It was necessary to insert variable declarations (e.g., double $\mathrm{x} ;$ ) into the $\mathrm{C \#}$ code. The following advantages have been found in the transition from Python to C\#:

- function, method, and constructor declarations are easier to understand because they specify variable types,

- programming errors can be found during program compilation,

- code executes faster (although execution speeds for ShipMo3D Python and C\# code are often similar because they use numerical libraries written in C),

- interoperability with other languages is generally easier, particularly when developing High Level Architecture federations.

\section{Application Programs}

ShipMo3D application programs read user input from an ASCII file and write computational results to an output ASCII file. The applications and documentation have been developed such that they can be used by both experts and non-experts. The applications PanelHull, RadDif, and BuildShip are used in consecutive order to build a model of a ship that can be used for subsequent motion predictions in either the time or frequency domain. The application BuildSeaway can build a seaway model, and FreeMo can 
simulate the ship motions in the seaway or in calm water. The applications SeakeepRegular, SeakeepRandom, and SeakeepSeaway perform frequency domain computations for a ship in regular or random waves.

Most ShipMo3D applications run within a few seconds. Evaluation of hull radiation and diffraction forces using RadDif requires approximately 1 hour, but only needs to be done once for a given ship loading condition. A typical RadDif run will use 1000 panels on the wetted hull surface and will evaluate terms for 60 encounter frequencies, 10 ship speeds, 13 relative sea directions, and 40 incident wave frequencies. Linear time domain simulations with FreeMo run much faster than real-time. Nonlinear time domain simulations usually run faster than real-time, with execution speed dependent on the number of hull panels and number of sinusoidal wave components used to represent the seaway.

A graphical user interface (GUI) has recently been developed for running ShipMo3D applications. The GUI facilitates entry of input parameters and interactive visualization of computational results.

\section{COMPARISONS WITH MODEL TESTS FOR A STEERED WARSHIP IN REGULAR WAVES OF SMALL STEEPNESS}

Lloyd and Crossland (1990) conducted a series of model tests for a steered warship with a nominal scale of $1 / 20$ in regular waves of small steepness (1/50). The experimental conditions included comprehensive coverage of speeds, relative sea directions, and wave frequencies. The model included 2 propellers and 2 rudders, which were controlled by autopilots with documented control settings. This experimental data set is arguably the best available for validating motion predictions in small amplitude waves.

The numerical predictions attempt to replicate the experimental conditions. The predictions in both the frequency and time domains model the autopilot used to control the rudder. The time domain predictions use a propeller RPM set to match ship speed in calm water, as was done when conducting the experiments. Due to the small wave steepnesses, the waves have little influence on model speed.

Figs. 1 and 2 show comparisons of predictions with model tests for one combination of speed (Froude number 0.27 ) and relative sea direction (120 degrees, bow quartering seas). Validation has also been conducted using 16 other combinations of ship speed and relative sea direction for which experiments were conducted. The numerical predictions agree generally well with the model tests. The roll motions are somewhat under-predicted at all wave frequencies for this combination of ship speed and heading. The experimental yaw motions are unexpectedly large at the lowest 4 frequencies.

The ShipMo3D predictions for the time domain and frequency domain are very similar. It should be noted that the time domain predictions include nonlinear hull maneuvering force coefficients and interactions between the rudders and propellers (i.e., influence of propeller slipstreams on rudders).
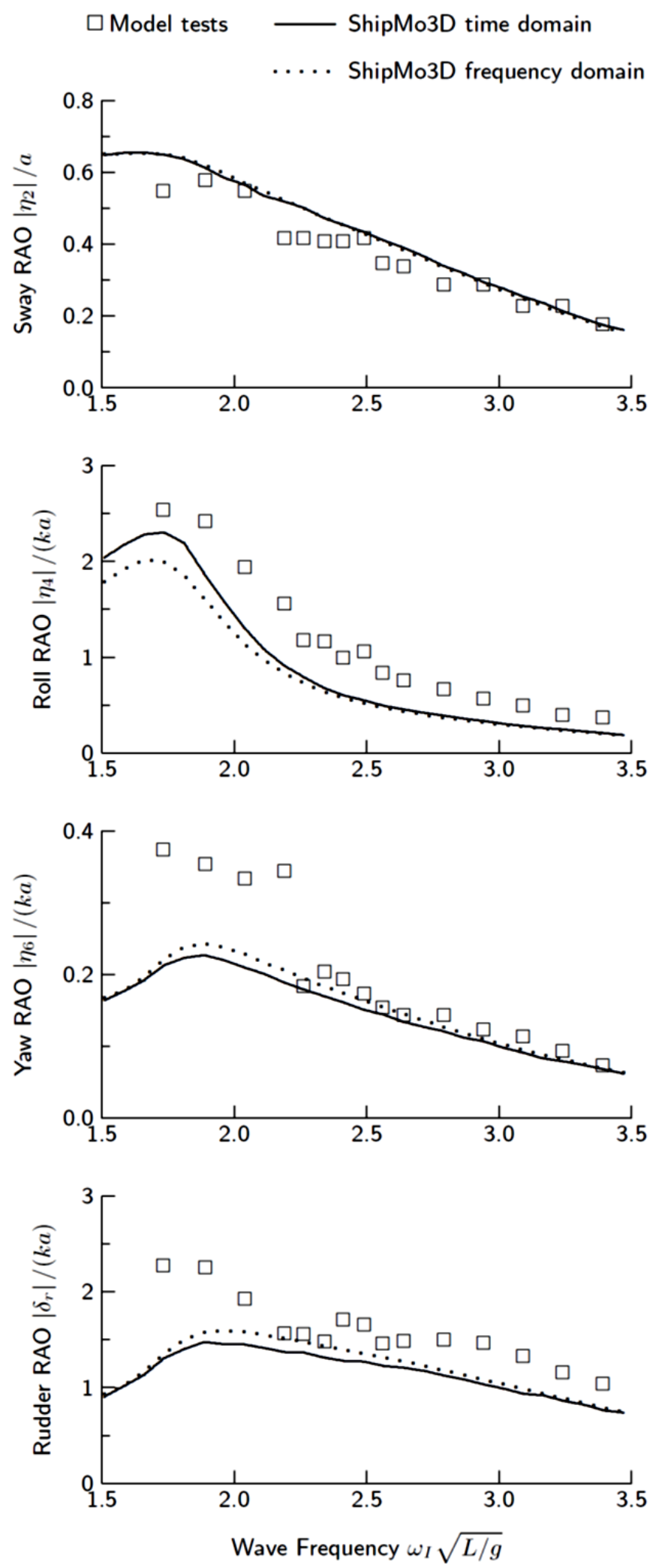

Fig. 1 Lateral plane RAOs for steered warship, bow quartering seas at 120 degrees, Froude number 0.27 . 




Fig. 2 Vertical plane RAOs for steered warship, bow quartering seas at 120 degrees, Froude number 0.27 .

The generally strong agreement between the experiments and numerical predictions suggests that the theoretical approach has been correctly implemented. Furthermore, the strong agreement between frequency domain and time domain predictions suggests that the theory and numerical implementation for converting forces from the frequency domain to the time domain are correct.

\section{COMPARISONS WITH MODEL TESTS FOR A FRIGATE IN REGULAR WAVES OF LARGER STEEPNESS}

McTaggart, Datta, Stirling, Gibson, and Glen (1997) describe model tests that were done with a hydroelastic model of a frigate. These model tests measured ship motions and sea loads for the model in both regular and random seaways. The experimental program included head seas tests in a towing tank and tests in head and oblique seas in a basin facility.

The present work considers model tests conducted in regular head seas in a towing tank. Experiments were conducted for wave steepnesses of $1 / 30,1 / 20$, and 1/15. The model was restrained in surge, sway, and yaw during the towing tank tests.
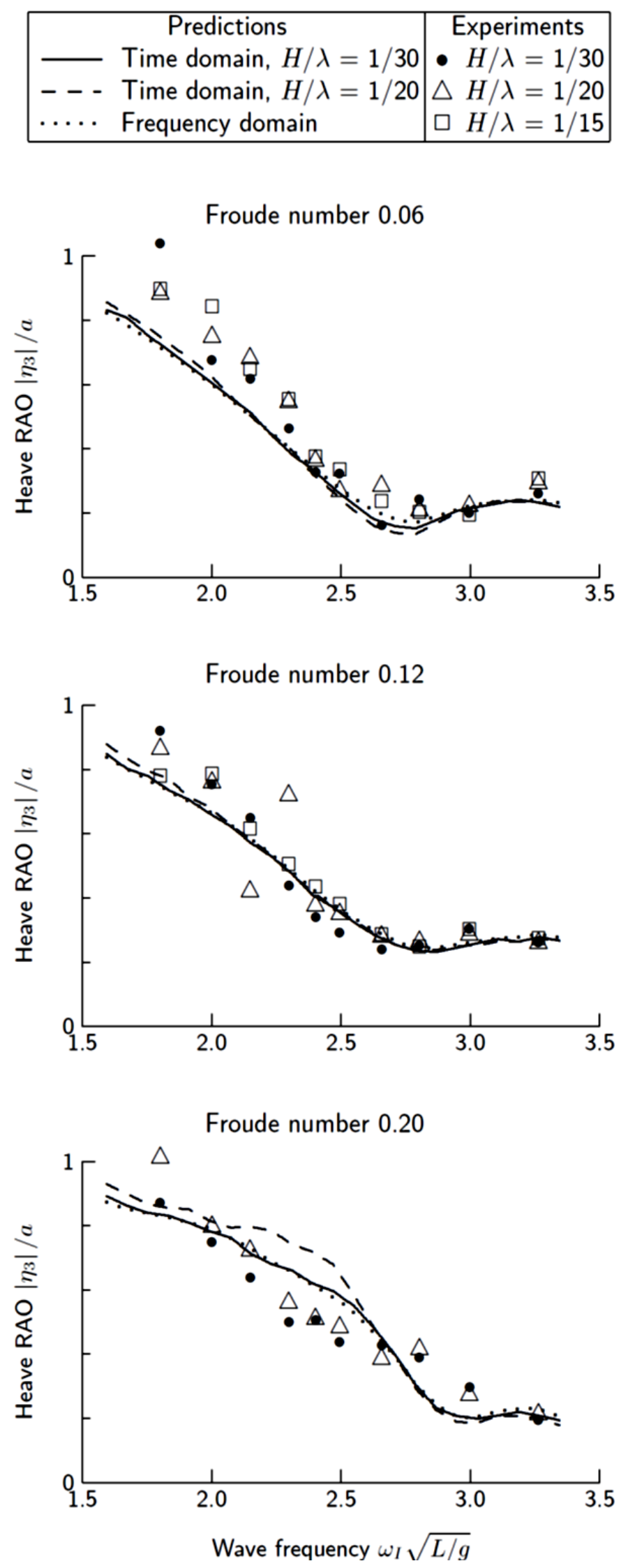

Fig. 3 Heave RAOs for Canadian Patrol Frigate Hydroelastic Model, Head Seas. 


\begin{tabular}{|c|c|}
\hline \multicolumn{1}{|c|}{ Predictions } & Experiments \\
\hline- Time domain, $H / \lambda=1 / 30$ & $\bullet H / \lambda=1 / 30$ \\
-- Time domain, $H / \lambda=1 / 20$ & $\triangle H / \lambda=1 / 20$ \\
$\cdots \quad$ Frequency domain & $\square H / \lambda=1 / 15$ \\
\hline
\end{tabular}
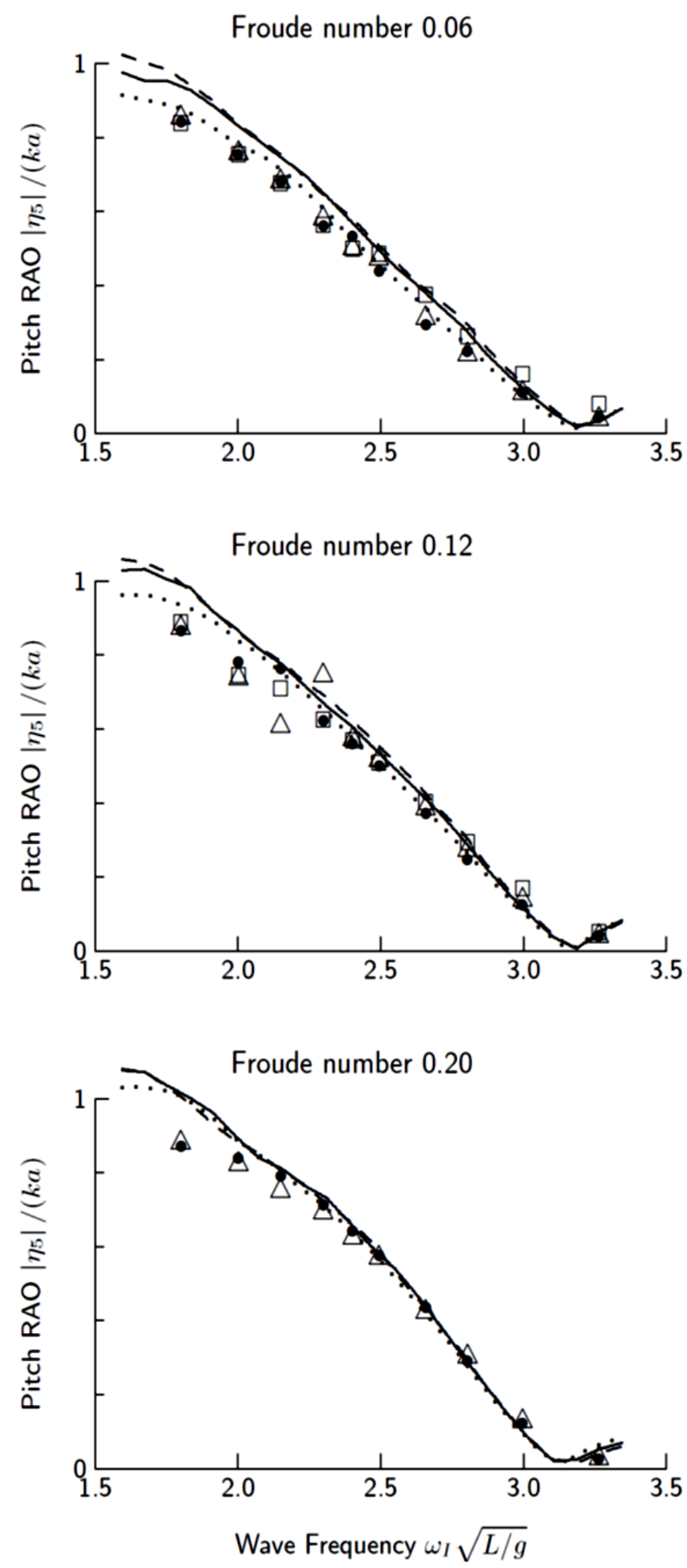

Fig. 4 Pitch RAOs for Canadian Patrol Frigate Hydroelastic Model, Head Seas.
For the numerical time domain computations, an iterative procedure was used to determine the propeller RPMs for a mean speed that would match the towing carriage speed for each combination of ship speed, wave frequency, and wave steepness. The numerical time domain predictions use nonlinear buoyancy and incident wave forces, with the seaway modelled using Stokes second-order theory.

The results in Figs. 3 and 4 show good agreement between the numerical predictions and the model tests. For wave steepnesses of $1 / 30$, the time domain predictions are nearly identical to the frequency domain predictions, suggesting that nonlinear effects are minor at the lowest wave steepness. Somewhat surprisingly, usage of nonlinear buoyancy and incident wave forces degrades agreement between predictions and experiments. The somewhat poorer agreement when using nonlinear buoyancy and incident wave forces could be caused partly by the usage of linear diffraction forces, causing an inconsistency in the treatment. It is postulated that introduction of nonlinear radiation and diffraction forces could lead to better agreement with experimental results.

COMPARISONS WITH SEA TRIALS FOR A NAVAL DESTROYER IN SIGNIFICANT WAVE HEIGHTS UP TO $6 m$

Stredulinsky, Pegg, and Gilroy (2000) conducted sea trials with the naval destroyer HMCS Nipigon (length $108 \mathrm{~m}$, displacement 3027 tonnes). Table 1 gives a summary of conditions for the sea trials.

Table 1 HMCS NIPIGON Trial Runs for ShipMo3D Validation.

\begin{tabular}{|c|c|c|c|c|}
\hline Run & Speed $(k t)$ & $H_{s}(m)$ & $T_{z}(s)$ & Relative sea dir \\
\hline 203 & 8 & 3.73 & 7.73 & Bow quarter \\
\hline 204 & 8 & 3.67 & 7.21 & Stern quarter \\
\hline 206 & 16 & 3.89 & 7.39 & Stern quarter \\
\hline 209 & 13 & 4.75 & 8.07 & Bow quarter \\
\hline 210 & 15 & 4.75 & 8.07 & Stern quarter \\
\hline 303 & 8 & 5.82 & 9.45 & Bow quarter \\
\hline 304 & 8 & 5.57 & 8.81 & Stern quarter \\
\hline 305 & 8 & 5.57 & 8.81 & Bow quarter \\
\hline 306 & 8 & 5.16 & 8.66 & Stern quarter \\
\hline 309 & 14 & 5.39 & 8.95 & Bow quarter \\
\hline 310 & 14 & 5.44 & 8.73 & Stern quarter \\
\hline 403 & 8 & 5.01 & 9.34 & Bow quarter \\
\hline 404 & 8 & 4.90 & 9.60 & Stern quarter \\
\hline 409 & 16 & 4.52 & 8.37 & Bow quarter \\
\hline 410 & 16 & 4.52 & 8.37 & Stern quarter \\
\hline 413 & 8 & 4.98 & 8.86 & Beam \\
\hline
\end{tabular}


Ship motions and structural strains were measured for the purpose of validating predictions of motions and sea loads. Directional wave spectra were measured using a wave buoy. McTaggart and Stredulinsky (2004) describe initial validation of ShipMo3D using data from the sea trials, with the initial time domain predictions being based on a ship with quasisteady speed and heading (i.e., not freely maneuvering). All ShipMo3D time domain predictions now are for a freely maneuvering ship.

To enable time domain simulations of sea trial conditions, models of the sea trial seaways were developed based on linear superposition of sinusoidal wave components. Amplitudes of modelled wave components were determined based on the observed directional wave spectral densities.

Figs. 5 and 6 show simulated versus observed values for significant wave heights and zero-crossing wave periods. The parameters for the simulated seaways are based on analysis of time series of wave elevation. Figs. 5 and 6 indicate that the simulated time series are providing suitable values of significant wave height and zerocrossing period.

Tables 2 and 3 and Figs. 7 and 8 show results of comparisons between predicted and measured ship motions. Predicted RMS motions and zero-crossing periods are typically within 10 percent of measured values, with the exception of roll, which is over-predicted by approximately 30 percent on average. Uncertainties in predicting roll could be due to several sources, including assumptions regarding the rudder deflections during the trial (an autopilot was assumed for numerical predictions), modelling of viscous roll damping, and nonlinear hull forces.

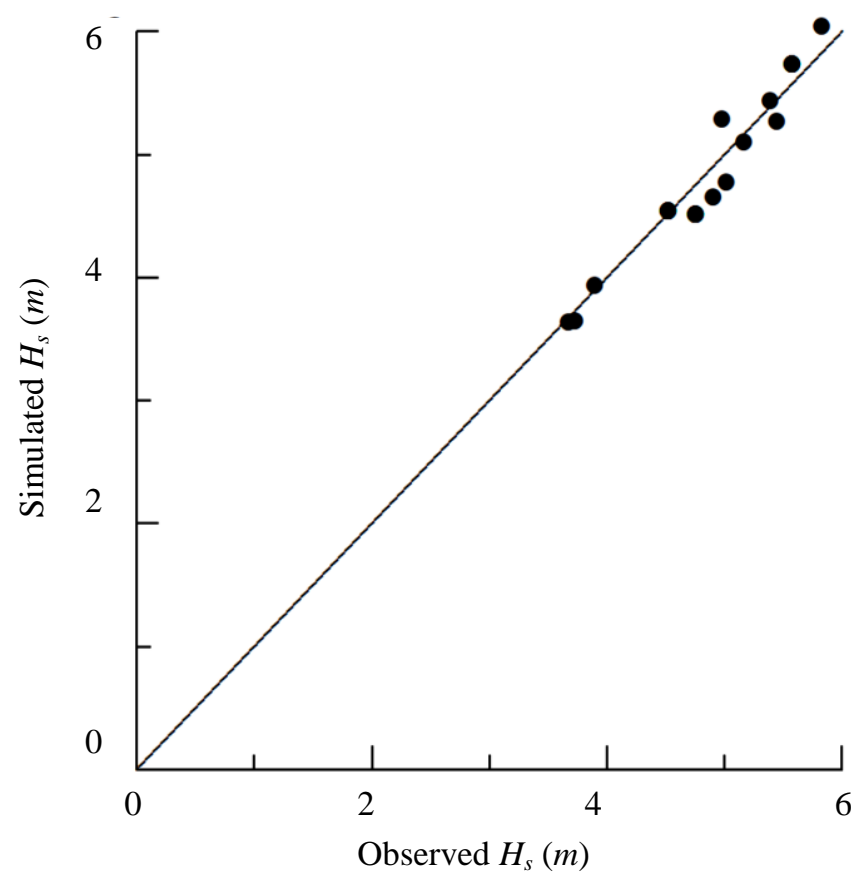

Fig. 5 Simulated Versus Observed Seaway Significant Wave Height for Sea Trials with HMCS Nipigon.

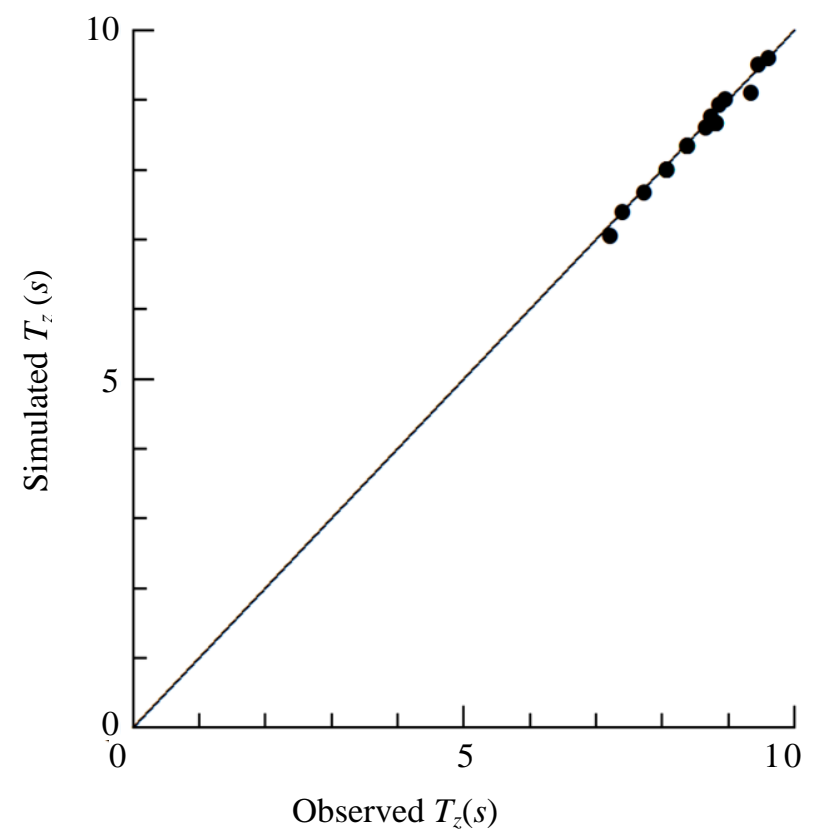

Fig. 6 Simulated Versus Observed Seaway Zero-Crossing Period for Sea Trials with HMCS Nipigon.

Table 2 Mean Ratio of Predicted to Observed RMS Motion and Zero-Crossing Period.

\begin{tabular}{|l|c|c|c|}
\hline & $\begin{array}{c}\text { Nonlinear } \\
\text { time domain }\end{array}$ & $\begin{array}{c}\text { Linear time } \\
\text { domain }\end{array}$ & $\begin{array}{c}\text { Frequency } \\
\text { domain }\end{array}$ \\
\hline Heave RMS & 0.93 & 0.93 & 0.93 \\
\hline Heave $T_{z}$ & 0.99 & 0.99 & 0.98 \\
\hline Roll RMS & 1.35 & 1.29 & 1.28 \\
\hline Roll $T_{z}$ & 1.02 & 1.04 & 1.04 \\
\hline Pitch RMS & 1.09 & 1.07 & 1.09 \\
\hline Pitch $T_{z}$ & 1.08 & 1.10 & 1.08 \\
\hline
\end{tabular}

Table 3 Standard Deviation of Ratio of Predicted to Observed RMS Motion and Zero-Crossing Period.

\begin{tabular}{|l|c|c|c|}
\hline & $\begin{array}{c}\text { Nonlinear } \\
\text { time domain }\end{array}$ & $\begin{array}{c}\text { Linear time } \\
\text { domain }\end{array}$ & $\begin{array}{c}\text { Frequency } \\
\text { domain }\end{array}$ \\
\hline Heave RMS & 0.15 & 0.16 & 0.15 \\
\hline Heave $T_{z}$ & 0.11 & 0.09 & 0.09 \\
\hline Roll RMS & 0.31 & 0.26 & 0.26 \\
\hline Roll $T_{z}$ & 0.06 & 0.07 & 0.06 \\
\hline Pitch RMS & 0.14 & 0.14 & 0.14 \\
\hline Pitch $T_{z}$ & 0.14 & 0.15 & 0.15 \\
\hline
\end{tabular}


+ Bow quarter

- Beam

$\circ$ Stern quarter
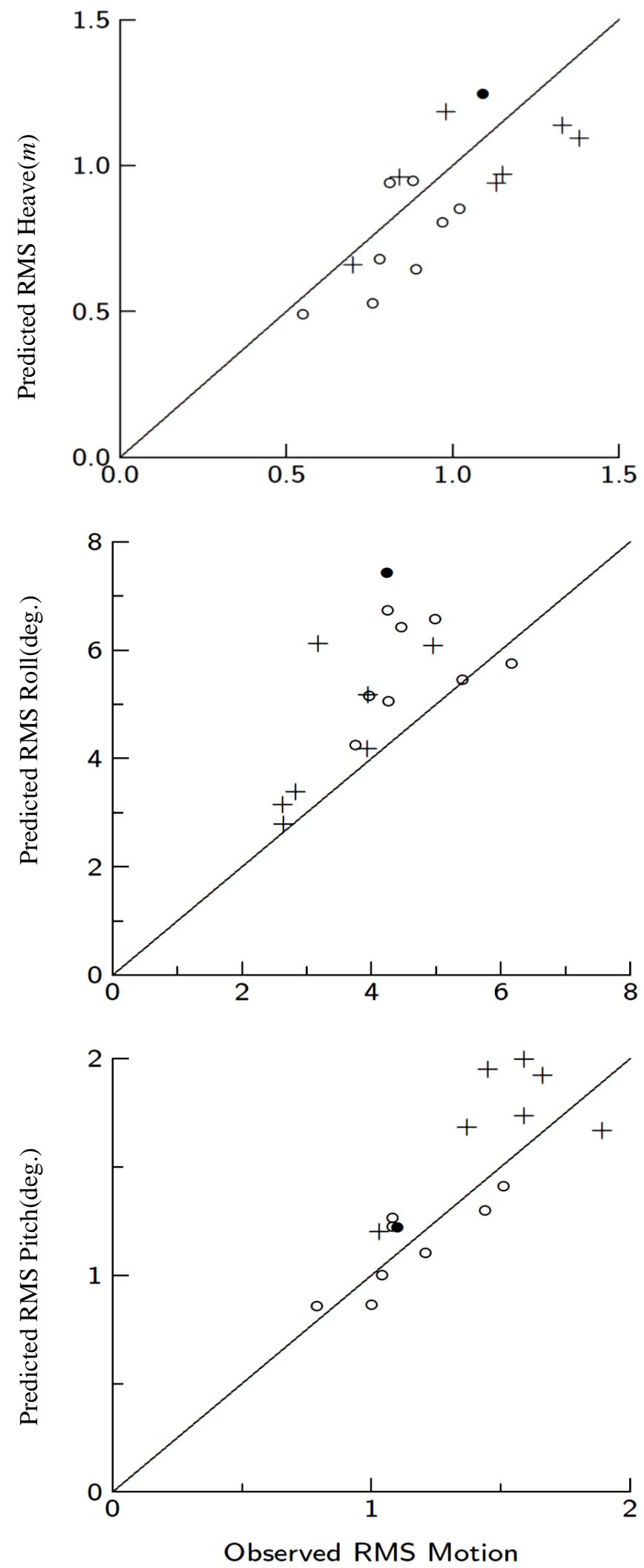

Fig. 7 Predicted (Linear Time Domain) Versus Observed RMS Motion for Sea Trials with HMCS Nipigon.
+ Bow quarter $\quad$ Beam $\circ$ Stern quarter
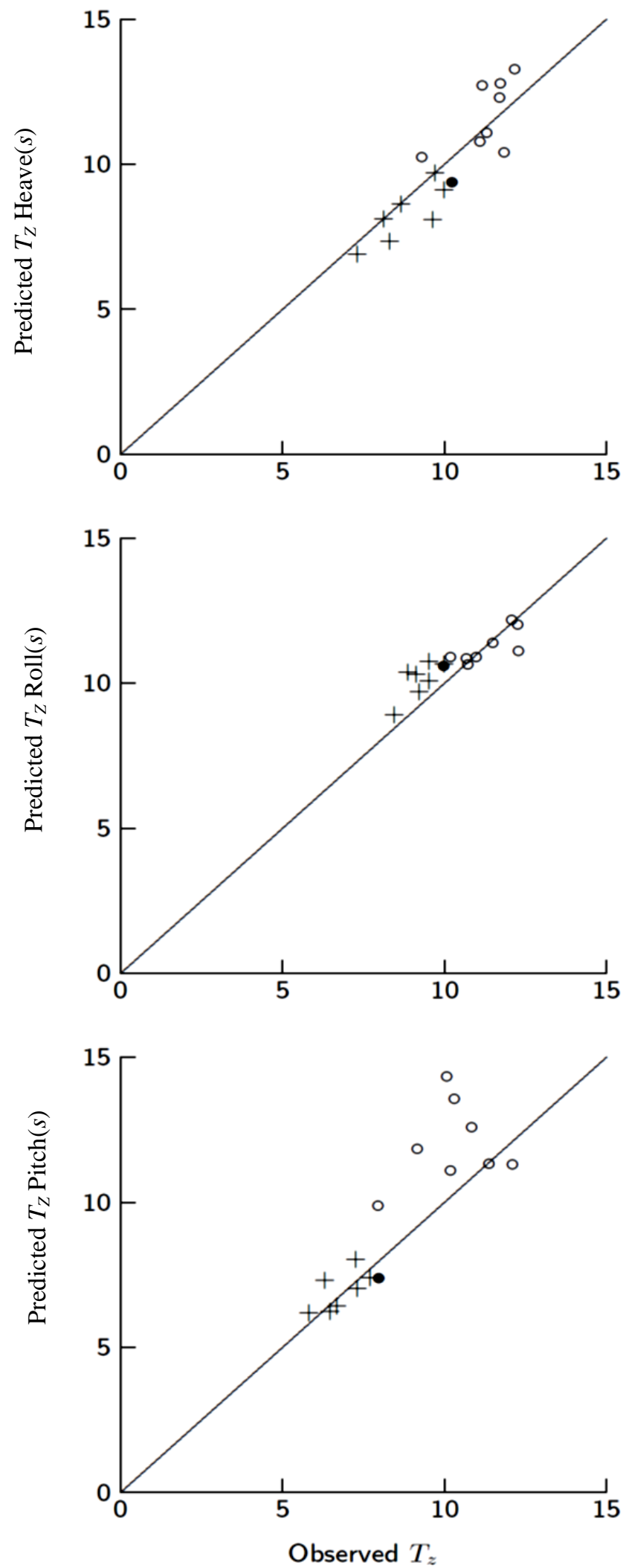

Fig. 8 Predicted (Linear Time Domain) Versus Observed Zero-Crossing Period for Sea Trials with HMCS Nipigon 
The results for frequency domain, linear time domain, and nonlinear time domain predictions are essentially the same, with the exception of nonlinear time domain predictions being slightly worse for RMS roll. Usage of nonlinear buoyancy and incident wave forces could cause poorer predictions because of inconsistent treatment of incident and diffraction excitation forces.

For pitch zero-crossing periods, Fig. 8 shows noticeable over-prediction in stern quartering seas, for which encounter periods are lower. This trend is likely due to violation of the assumption of high encounter frequency when evaluating radiation and diffraction coefficients.

\section{DISCUSSION}

Verification and validation to date suggest that the theory behind ShipMo3D has been implemented correctly. Several valuable lessons have been learned that can guide usage and further development of numerical predictions.

\section{Zero Forward Speed Green Function for Evaluation of Hull Hydrodynamic Forces}

Validation work to date suggests that the Green function for zero forward speed leads to satisfactory ship motion predictions for ships with forward speed Froude numbers less than 0.4. This conclusion is consistent with findings from Schellin, Chen, Beiersdorf and Maron (2002). When using the zero forward speed Green function for a given ship loading condition, the Green function only needs to be evaluated for a limited number of encounter frequencies (e.g., $60)$. Furthermore, computations of the Green function are not required at multiple ship speeds. In practice, small numbers of irregular frequencies usually occur, and these can be easily removed based on observed computational results.

ShipMo3D computations to date assume that the scattered steady flow potential is negligible. Evaluation of the scattered steady flow potential is very simple using a double body approximation, and will be implemented to give improved evaluation of $m$-terms and resulting hydrodynamic forces at forward speed. Implementation of a forward speed Green function (either time domain or frequency domain) will be considered as the need arises.

\section{Frequency Domain and Time Domain Predictions}

The present frequency domain and linear time domain predictions give very consistent results and very good agreement with experiments in moderate wave conditions, suggesting that the frequency domain and time domain theoretical approaches have been correctly implemented.

When performing validation of time domain predictions, it is important to match computed mean ship speed with observed mean ship speed. An iterative approach can be used to adjust propeller RPM such that the correct ship speed is obtained for time domain simulations in a given seaway.
Experience with practical application of ship motion predictions has shown that frequency domain computations are often more suitable than time domain computations. Frequency domain computations are very convenient in terms of amount of input and output data, computational time, and availability of statistical output data. Time domain analysis is more complex and often doesn't provide any practical advantages. Time domain simulations are very useful in some instances, such as training or simulation of interactions with other systems (McTaggart and Langlois, 2009).

\section{Nonlinear Hull Hydrodynamic Forces}

The present work indicates that evaluation of nonlinear buoyancy and incident wave forces using the instantaneous wetted hull surface doesn't give improved motion predictions. This result could be due to the inconsistency in the treatment of incident and diffracted wave forces.

Future work should examine treatment of nonlinear radiation and diffraction forces. For example, frequency domain radiation and diffraction forces could be evaluated for a variety of local drafts and roll angles relative to the local sea surface, with results used in subsequent nonlinear time domain computations.

\section{Model Experiments and Sea Trials}

Model experiments and sea trials are both essential for validating ship motion predictions. Model tests offer advantages in terms of being able to control and measure experimental conditions. It is essential that predictions be validated in regular waves of low amplitude before moving on to more complex conditions.

Full-scale sea trials offer the advantage of not suffering from scale effects; however, scale effects are likely minimal for seakeeping tests conducted with models of reasonable size. When validating predictions using data from sea trials, accurate measurements of directional wave spectra are essential, with a directional wave buoy typically being deployed in the trials area.

\section{Roll Motions}

Consistently accurate prediction of roll motions remains a significant challenge for seakeeping codes. Roll motion predictions are used for many naval design and operational applications. More accurate roll motion predictions will likely come with better understanding of viscous forces acting on hulls and appendages. Associated advances are being made with computational fluid dynamics.

\section{CONCLUSIONS}

Ship motion predictions based on the Green function for zero forward speed give generally good results in both the 
frequency and time domain for ships travelling at moderate speed. The present evaluation of nonlinear buoyancy and incident wave forces based on the instantaneous wetted hull surface does not lead to improved motion predictions, possibly due to the associated inconsistent treatment of incident and diffracted wave force components. Consistently accurate prediction of roll motions remains a challenge for seakeeping codes due to the influence of viscous effects.

\section{REFERENCES}

De Kat, J.O. Brouwer, R. McTaggart, K. and Thomas, L., 1994. Intact Ship Survivability in Extreme Waves: Criteria from a Research and Navy Perspective. 5th International Conference on Stability of Ships and Ocean Vehicles, Melbourne, Florida, USA.

Himeno, Y., 1981. Prediction of Ship Roll Damping - State of the Art. Report 239, Department of Naval Architecture and Marine Engineering, University of Michigan, USA.

Inoue, S. Hirano., M. and Kijima, K., 1981. Hydrodynamic Derivatives on Ship Manoeuvring. International Shipbuilding Progress, 28(321), pp.112-125.

Kuhl, F. Weatherly, R. and Dahmann, J., 1999. Creating Computer Simulation Systems - An Introduction to the High Level Architecture. Prentice Hall PTR, Upper Saddle River, New Jersey. USA.

Lloyd, A.R.J.M. and Crossland, P., 1990. Motions of a Steered Model Warship in Oblique Waves. Transactions, Royal Institution of Naval Architects, Vol. 132, pp.79-98.

McTaggart, K., 2006. Simulation of Ship Motions with Python. SimTecT 2006, Melbourne, Australia.
McTaggart, K. Datta, I. Stirling, A. Gibson, S. and Glen, I., 1997. Motions and Loads of a Hydroelastic Frigate Model in Severe Seas. Transactions, Society of Naval Architects and Marine Engineers, Vol. 105, pp.427-453

McTaggart, K. and de Kat, J.O., 2000. Capsize Risk of Intact Frigates in Irregular Seas. Transactions, Society of Naval Architects and Marine Engineers, Vol. 108, pp. 147-177.

McTaggart, K. and Langlois, R., 2009. Physics-based modelling of ship replenishment at sea using distributed simulation. SNAME Annual Meeting and Expo, Providence. RI, USA.

McTaggart, K. and Stredulinsky, D., 2004. Validation of Ship Motion Predictions with Sea Trials Data for a Naval Destroyer in Multidirectional Seas. 25th Symposium on Naval Hydrodynamics, St. John's, Canada.

Papanikolaou, A.D. and Schellin, T.E., 1992. A ThreeDimensional Panel Method for Motions and Loads of Ships with Forward Speed. Schiffstechnik, Vol. 39, pp. 147-156.

Salvesen, N. Tuck, E.O. and Faltinsen, O., 1970. Ship Motions and Sea Loads. Transactions, Society of Naval Architects and Marine Engineers, Vol. 78, pp.250-287.

Schellin, T.E., Chen, X.-B., Beiersdorf C., and Maron, A., 2002. Comparative Frequency Domain Seakeeping Analysis of a Fast Monohull in Regular Head Waves. 21st International Conference on Offshore Mechanics and Arctic Engineering, Oslo, Norway.

Schmitke, R.T., 1978. Ship Sway, Roll, and Yaw Motions in Oblique Seas. Transactions, Society of Naval Architects and Marine Engineers, Vol. 86, pp.26-46.

Stredulinsky, D.C. Pegg, N.G. and Gilroy, L.E., 2000. Motion and Wave Load Predictions and Measurements on HMCS NIPIGON. Transactions, Royal Institution of Naval Architects, Vol. 142, pp. 248-258.

Wehausen, J.V., 1971. The Motion of Floating Bodies. Annual Review of Fluid Mechanics, Vol. 3, pp. 237-268. 